Von nicht tuberkulösen Kindern 16 per cent. typische Hautreaktion zeigten; nicht tuberkulöse Erwachsene und grössere Kinder reagiren sehr leicht bezw. ohne Ausnahme.

I do not deny that there is some significance in the cutaneous reaction, but its significance when the reaction is only cutaneous is possibly non-specific, and when the reaction through some peculiarity of the skin of the tested individual becomes specific it may be violent and, therefore, dangerous, as the dose is too high and can not be graded. Whatever was said in reference to the cutaneous reaction, relates also, though not to the same extent, to the ophthalmic. In the ophthalmic test we use two minims ordinarily of 1 per cent. solution of pure tuberculin, or 1.2 of pure tuberculin. If we should suppose that half of it was wasted, and this is hardly the case, as we use no applicator with it, but drop it directly into the conjunctival sac, hold it for a few seconds until it spreads all over-then we instil into the conjunctiva, a membrane of great absorbent powers, 0.6 mg., a dose which is too high for the initial dose. If it gives no general or focal specific reaction the fault is not ours, but in all probability that the tuberculin acts in the conjunctiva only as an irritant, and the more sensitive and prone to irritation the conjunctiva is the more or less pronounced will be the conjunctivitis, irrespective of the circumstances, whether the subject tested is tuberculous or not.

Whatever was said about the cutaneous and ophthal. mic reactions relates also to the Moro test.

84 Academy street.

\section{A CASE OF BILATERAL RENAL CALCULI}

$$
\text { DANIEL N. EISENDRATH, A.B., M.D. }
$$

The following case illustrates the necessity of taking skiagraphs of both kidneys in every case of suspected renal calculi. It is a generally accepted fact that the simultaneous presence of calculi in both kidneys is not so rare as was formerly thought. It has been estimated to occur in from 15 to 20 per cent. of cases of nephrolithiasis. It is of the utmost importance to ascertain the bilateral presence of calculi, owing to the frequency with which anuria may occur, with obstruction of the ureter of one side and reflex inhibition of the functional activity of the opposite kidney or cessation of the secretory functions of the latter as the result of blocking of its ureter by a calculus. It is beyond the province of this brief clinical report to discuss the advisability of operating on one or both kidneys at the same sitting. At present I am inclined to believe that the method pursued in this case of operating at an interval of four to six weeks is the safer one. The history of my case is as follows:

History-E. H., aged 20, was referred by Dr. Mortimer Frank of Chicago. In 1903 (five years prior to my first examination) the patient began to have pains alternately over the right and left lumbar regions. Up to one year before my examination tne pain had been chiefly in the right side, but during the year preceding my examination the pain had been confined to the left side. The pain was of an aching character, lasting several hours, and localized over the left kidney. The urine had been cloudy for past four years. Neither blood nor calculi were ever passed until July, 1908, when he had severe pain over the left kidney for three days, accompanied by chills, fever and the passage of a few small calculi and some blood, the last-named symptom persisting for one day. Since this attack pain occurred only on the left side. Skiagraphs, taken s:parately of the right and left kidneys, revealed the presence of undoubted stone shadows in both. Functional tests with indigo-carmin and phloridzin showed both kidneys of about equal functional capacity.

First Operation.-The calculi were removed from the left kidney on Oct. 30,1908 . The kidney was converted into a number of hydronephrotic cavities, with only a narrow rim of parenchyma. After splitting the kidney in the median line of its convexity, thirteen calculi were found. One of these almost completely blocked the pelvic orifice of the ureter. The remainder of the calculi were found in the greatly dilated calices of the hydronephrotic kidney. On account of the presence of a fair amount of good parenchyma at the upper and lower poles, it was deemed best not to remove the kidney.

The patient recovered very rapidly from this operation and left the hospital on Nov, 26, 1908.

Second operation.- He re-entered the Michael Reese Hospital on Feb. 3, 1909, to have the calculi removed from the right kidney. Nephrotomy on this side was performed in the usual manner, and six calculi, varying in size from a pea to a lima bean, were removed. One of these calculi incompletely blocked the pelvic orifice of the ureter, as in the other kidney. This right kidney showed even more advanced changes than the left. It was greatly sacculated, so that the calculi could be readily palpated through its thin walls. The parenchyma was apparently destroyed in the upper half, the only functionailng portion being in the lower half. One stone, the size of a hazel-nut, was in the lower pole near the cortex; a second, the size of a hickory-nut, lay in the pelvis, and a third large stone was in the upper pole. The other three calculi lay in the sacs near the cortex.

The patient also made an uneventful recovery from this second nephrotomy and returned to work four weeks later. The wound was healed six weeks after the operation. He has gained greatly in weight and color.

103 State street.

\section{TRYPSIN IN POSTOPERATIVE TREATMENT OF CARCINOMA OF BREAST}

\section{JOSEPH JEROME CRONIN, M.D. ROXBURY, MASS.}

History.-On Sept. 17, 1907, I was called to see Mrs. S., aged 62 , who had a growth in the left breast and considerable pain. She said it had been growing for more than a year, but she had never consulted a physician about it. On examination I found the breast very large with skin adherent for some distance around the nipple area, and several thickened carcinomatous patches in the skin. The glands in the neck and axilla were much enlarged. I advised immediate operation, but the patient was opposed to this. I saw her again on Sept. 28, 1907. The pain had increased a great deal and the patient had considerable vomiting, complained of chills and had an unquenchable thirst. She had the typical eachectic color. The skin showed more thickening and discoloration. I removed the breast by the usual radical operation on October 3, removing all the glands in the axilla and a large area of skin. I obtained primary union in the usual time, but the patient had failed a great deal since the operation. A general toxemia, probably due to the cancer, had been uresent since before the operation. The patient had a temperature of 100 to 101 and always a rapid pulse, with persistent vomiting and thirst. She failed rapidly in weight and strength. Examination of urine, stools and stomach contents, from time to time, showed nothing abnormal.

Use of Trypsin.-On Feb. 3, 1908, I began the use of trypsin and amylopsin. The patient stood the treatment very well; had no local reaction or abcesses. After a few months, vomiting ceased except at intervals, when an injection of amylopsin would seem to control it for another period. The patient has now had no treatment since Nov. 11, 1908; is down stairs every day and assists occasionally in light housework. Her appetite is much improved. She is in better condition since the operation and the treatment has certainly helped her.

It is certainly well worth a trial, and I am now using it in two more cases, but it is too early as yet to make any deduction in these cases. 